\title{
Identificação de genótipos de feijão-caupi tolerantes e suscetíveis ao déficit hídrico
}

\author{
Eveline Nogueira LIMA ${ }^{1 *}$, Kátia Regina Alves PIRES ${ }^{1}$, Elaine Facco CELIN ${ }^{1}$, \\ Cândida Hermínia Campos de Magalhães BERTINI ${ }^{1}$, Rosilene Oliveira MESQUISTA ${ }^{1}$
}

${ }^{1}$ Programa de Pós-Graduação em Agronomia (Fitotecnia), Universidade Federal do Ceará, Fortaleza, CE, Brasil.
*E-mail:evelinenlima@gmail.com

Recebido em outubro/2017; Aceito em agosto/2018.

\begin{abstract}
RESUMO: Objetivou-se com esse trabalho identificar genótipos de feijão-caupi tolerantes e suscetíveis ao déficit hídrico, utilizando-se duas metodologias, estresse hídrico simulado com o uso de PEG6000 (Polietilenoglicol) e Screening Box. Os experimentos foram conduzidos em casa de vegetação no delineamento inteiramente casualizado com três repetições. Para a metodologia com PEG6000 foram utilizados 15 genótipos e duas testemunhas, com três repetições, totalizando 90 amostras. Foram selecionadas seis plântulas por genótipo, utilizaram-se três caixas contendo apenas água destilada e outras três com nível de potencial osmótico de - 0,2 MPa de PEG6000. A avaliação foi feita até atingir o ponto máximo de crescimento das raízes. Para a metodologia de Screening Box foram utilizados 15 genótipos, onde estes foram avaliados quanto à tolerância ao déficit hídrico no estádio de plântula. As duas metodologias mostraram-se eficientes na seleção de genótipos de feijão-caupi, os genótipos Santo Inácio Vermelho e BRS Tumucumaque, foram os mais sensíveis à seca, em ambas as metodologias.
\end{abstract}

Palavras-chave: Vigna unguiculata, seca, plântulas.

\section{Cowpea genotypes tolerant and susceptible to water deficit}

\begin{abstract}
Objective to identify tolerant and susceptible cowpeas genotypes to water deficiency at the seedlings stage of growth, using two methodologies such as (a) water stress with the use of PEG6000 (Polyethylene glycol) and the Screening Box were used in the present research. The experiments were conducted in greenhouse environments using a completely randomized design with three replications. For the PEG6000 approach, 15 genotypes and two controls treatments were used in three replications in a total of 90 samples. Six seedlings were selected per genotype by using three boxes containing only distilled water. In the other treatment, three level of osmotic potential of $-0.2 \mathrm{MPa}$ of PEG6000. The evaluations of the trials were done until the Screening Box approach, 15 genotypes were used and were evaluated for tolerance to water deficit at the seedling stage of growth. The two methodologies were efficient in the selection of cowpea genotypes, the genotypes Santo InácioVermelho and BRS Tumucumaque were the most sensitive to drought in both methodologies.
\end{abstract}

Keywords: drought, Vigna unguiculata, seedlings.

\section{INTRODUÇÃO}

O feijão-caupi [Vigna unguiculata (L.) Walp.] é considerado uma cultura nativa da África ocidental e uma das mais importantes culturas de legumes cultivadas em trópicos semiáridos; Ásia; África; sudeste da Europa; e América Central e do Sul, especificamente pelo seu desenvolvimento e capacidade de produção em áreas onde outras culturas não crescem bem devido a altas temperaturas e chuvas erráticas (FREITAS et al., 2017).

No Brasil, é mais cultivado nas regiões Norte e Nordeste, sendo o Nordeste aquela que tem uma condição comum de déficit hídrico, um dos fatores que comumente reduz a produtividade do feijão-caupi (MENDES et al., 2007). O requerimento de água desta cultura é variável com o seu estádio de desenvolvimento (NASCIMENTO et al., 2011) e apesar de ser considerado tolerante a baixas condições de disponibilidade de água quando comparado a outras culturas, como por exemplo, o feijão comum (Phaseolus vulgaris), o feijão-caupi é moderadamente sensível ao estresse hídrico (GWATHMEY; HALL, 1992). Entretanto, o grau de tolerância do feijão-caupi ao estresse hídrico varia entre genótipos (COELHO et al., 2013).

Nos programas de melhoramento de feijão-caupi, a seleção de genótipos com características de tolerância à seca é importante para garantir a produção, principalmente nas regiões do semiárido onde ocorre má distribuição de chuvas e, períodos prolongados de seca. Alguns estudos já estão sendo desenvolvidos e recomendados para se identificar plantas mais adaptadas à baixa disponibilidade de água no solo (ASSIS JUNIOR et al., 2007).

Nesse sentido, se encontra o uso do polietilenoglicol (PEG6000) um composto inerte não tóxico (FERREIRA et al., 2017), que simula os efeitos da restrição hídrica por não penetrar nas células, não ser degradado e não causar toxidez, devido ao seu alto peso molecular (SOUZA; CARDOSO, 2000), atuando como um agente osmótico por simular um determinado potencial osmótico (广os) (SOUZA; CARDOSO, 2000).

Outra metodologia utilizada é a descrito por Singh et al. (1999a), denominada de "Screening Box", que trata-se de um método simples de triagem em caixa de madeira, onde podem 
ser selecionadas plantas tolerantes à seca ou progênies de feijão-caupi na fase de plântulas. Essa metodologia difere dos outros métodos que são considerados dispendiosos e demorados, além disso, a seleção em condições de campo nem sempre é possível devido à impossibilidade e a intensidade do estresse pela seca (SINGH; MATSUI, 2002).

No melhoramento de plantas uma das primeiras etapas é a identificação de genótipos que apresentem caracteres superiores ou desejáveis ao desenvolvimento de novos cultivares, como por exemplo, genótipos com tolerância à seca. Diante do exposto, objetivou-se identificar genótipos de feijão-caupi tolerantes e suscetíveis ao déficit hídrico a nível de plântulas, utilizando-se as metodologias, de estresse hídrico simulado com o uso de PEG6000 (Polietilenoglicol) e Screening Box descrito por Singh et al. (1999a).

\section{MATERIAL E MÉTODOS}

2.1 Local e preparo do material vegetal

$\mathrm{O}$ experimento foi conduzido em casa de vegetação na Universidade Federal do Ceará, Fortaleza-CE. Para simular o estresse hídrico foram utilizadas duas metodologias: PEG6000 (Polietilenoglicol) e Screening Box. Em ambos os experimentos foram utilizados 15 genótipos (Tabela 1) e as sementes foram induzidas a germinação antes de serem introduzidas nos tratamentos.

Para a germinação, 12 sementes de cada genótipo foram esterilizadas com $\mathrm{NaOCl}$ a $0,5 \%$ por 1 min., lavadas com água destilada e, posteriormente, distribuídas sobre duas folhas de papel germiteste umedecidas com água destilada, em quantidade equivalente a 2,5 vezes a massa do papel seco e formados rolos. Os rolos de papel germiteste foram colocados em Becker e transferidos para um germinador com temperatura de $25{ }^{\circ} \mathrm{C}$ por $48 \mathrm{~h}$, tempo suficiente para a emissão da radícula $(1-2 \mathrm{~cm})$.

\subsection{Estresse hídrico simulado com o uso de PEG6000} (Polietilenoglicol)

Seis plântulas por genótipo foram selecionadas, com radícula de 1 a $2 \mathrm{~mm}$ de comprimento, para ser fixadas em duas folhas de papel germiteste de tamanho A4, envolvidas por um saco de polietileno transparente perfurado (exsicata).

Essas folhas foram colocadas verticalmente em uma caixa de madeira com dimensões $37 \times 30 \times 50 \mathrm{~cm}$ (largura x altura $\mathrm{x}$ comprimento). No fundo da caixa, em uma bandeja de polietileno, foi depositada água destilada ou solução de PEG6000 (119,571 g.L - $^{-1}$ de água destilada), no nível de potencial osmótico de $-0,2 \mathrm{MPa}$. A parte superior da exsicata ficou apoiada nas laterais da caixa de madeira e a parte inferior imersa na solução, que por capilaridade umedecia o papel, onde se desenvolveu o sistema radicular. As caixas foram mantidas em casa de vegetação a uma temperatura de $25 \pm 3{ }^{\circ} \mathrm{C}$ até o momento das avaliações.

A avaliação foi realizada ao longo de cinco dias, sendo mensurados: comprimento total da raiz principal (diariamente e no mesmo horário), número de raízes laterais, número de verticilos e massa seca dos 15 genótipos de feijão-caupi submetidos às duas situações, à solução de PEG6000 e a água. A avaliação foi feita até atingir o ponto máximo de crescimento das raízes (tamanho da folha A4).

$\mathrm{O}$ experimento foi conduzido em delineamento inteiramente casualizado, com três repetições. $\mathrm{Na}$ análise estatística foi realizado o teste de médias pelo teste de Tukey a 5\% de probabilidade utilizando o programa estatístico Sisvar (FERREIRA, 2011).

Tabela 1. Descrição dos genótipos avaliados quanto à tolerância ao déficit hídrico.

Table 1. Description of genotypes assessed for water deficit tolerance.

\begin{tabular}{|c|c|c|}
\hline $\mathrm{N}^{\mathrm{o}}$ & Genótipos & Dados de origem \\
\hline 1 & Pitiuba & $\begin{array}{l}\text { (BAG/UFC/Universidade Federal } \\
\text { do Ceará) }\end{array}$ \\
\hline 2 & Patativa & $\begin{array}{l}\text { (BAG/UFC/Universidade Federal } \\
\text { do Ceará) }\end{array}$ \\
\hline 3 & Epace 10 & (BAG/UFC/ EPACE) \\
\hline 4 & Sempre Verde & $\begin{array}{l}\text { (BAGUFC/Universidade Federal do } \\
\text { Ceará) }\end{array}$ \\
\hline 5 & Setentão & $\begin{array}{l}\text { (BAG/UFC/Universidade Federal } \\
\text { do Ceará) }\end{array}$ \\
\hline 6 & Pingo de Ouro & $\begin{array}{l}\text { (BAG/UFC/Universidade Federal } \\
\text { do Ceará) }\end{array}$ \\
\hline 7 & Pingo de Ouro 1, 2 & (BAG/Embrapa Meio Norte) \\
\hline 8 & BRS Pageú & Produtor Parambu-Ce \\
\hline 9 & $\begin{array}{l}\text { Santo Inácio } \\
\text { Vermelho }\end{array}$ & Produtor Parambu-Ce \\
\hline 10 & CNCX 251-76E & (CNPAF) \\
\hline 11 & Roxinho 1 & (BAG/UFC/ Acarape - Ce) \\
\hline 12 & BRS Punjante & (Cultivar Embrapa Meio Norte) \\
\hline 13 & BRS Paraguaçu & (Cultivar Embrapa Meio Norte) \\
\hline 14 & BRS Tumucumaque & (Cultivar Embrapa Meio Norte) \\
\hline 15 & BRS Marataoã & (Cultivar Embrapa Meio Norte) \\
\hline
\end{tabular}

2.3. Estresse hídrico simulado com o método do Screening Box

Para esse experimento seguiu a metodologia proposta por Singh et al. (1999a), com algumas modificações. As sementes germinadas foram semeadas em bandejas de plástico (53 cm de comprimento, $37 \mathrm{~cm}$ de largura e $24 \mathrm{~cm}$ de profundidade). As bandejas foram preenchidas com uma mistura de 6:3:1 de areia, húmus de minhoca e vermiculita, respectivamente. Estas foram preenchidas com uma profundidade de $18 \mathrm{~cm}$, deixando-se cerca de $6 \mathrm{~cm}$ de espaço na parte superior para a rega. Orifícios equidistantes foram feitos em linhas retas, para introdução das sementes. Cada bandeja continha uma linha de cada genótipo de feijão-caupi, com sete plantas.

Os tratamentos foram dispostos em cinco repetições ao acaso. As bandejas foram irrigadas até o $9^{\circ}$ dia. Após este período, foi cessada totalmente a irrigação de quatro bandejas e uma repetição continuou sendo irrigada. Todos os dias foram avaliados o número de plantas vivas e o número de plantas mortas. A partir do teste de Scott; Knott (1974) e traçada uma curva de murcha permanente e, os genótipos foram classificados como tolerante ou sensível à seca.

\section{RESULTADOS}

3.1. Estresse hídrico simulado com o uso de PEG6000 (Polietilenoglicol)

Houve efeito significativo $(\mathrm{P}<0,05)$ entre os tratamentos genótipos versus tratamentos para altura final (Tabela 2) e taxa de crescimento (Tabela 3) havendo uma interação significativa. O genótipo CNCX 251-76E se destacou quanto ao comprimento final com o tratamento PEG6000 (polietileno glicol).Os demais genótipos não diferiram estatisticamente, sendo que os comprimentos das raízes ficaram comprometidos quando submetidos ao tratamento 
PEG6000. Alguns genótipos, como CNCX 251-76E e Pingo de ouro 1,2 também diferiram dos demais quando submetido ao tratamento com água.

Em relação à taxa de crescimento (Tabela 3), no tratamento PEG6000 o genótipo que diferiu dos demais foi CNCX 251-76E, havendo uma maior taxa de crescimento.

Tabela 2. Comprimento total $(\mathrm{cm})$ das raízes aos cinco dias após a semeadura e submetidas ao tratamento com água e PEG6000.

Table 2. Total length $(\mathrm{cm})$ of the roots at five days after sowing and submitted to treatment with water and PEG6000.

\begin{tabular}{lcc}
\hline Genótipos & PEG6000 & $*$ Água \\
\hline Pituba & $6,36 \pm 1,8 \mathrm{Bb}$ & $20,5 \pm 3,7 \mathrm{Aabc}$ \\
Patativa & $5,00 \pm 1,2 \mathrm{Bb}$ & $20,7 \pm 5,4 \mathrm{Aabc}$ \\
EPACE 10 & $6,16 \pm 0,5 \mathrm{Bb}$ & $15,2 \pm 2,4 \mathrm{Acde}$ \\
Sempre Verde & $4,83 \pm 0,6 \mathrm{Bb}$ & $18,6 \pm 7,4 \mathrm{Aabcd}$ \\
Setentão & $3,93 \pm 0,5 \mathrm{Bb}$ & $13,8 \pm 2,5 \mathrm{Acde}$ \\
Pingo de Ouro & $4,53 \pm 1,1 \mathrm{Bb}$ & $8,53 \pm 2,9 \mathrm{Ae}$ \\
Pingo de Ouro 1,2 & $6,7 \pm 1,0 \mathrm{Bb}$ & $25,8 \pm 4,4 \mathrm{Aab}$ \\
Pageú & $4,16 \pm 1,8 \mathrm{Bb}$ & $17,0 \pm 1,9 \mathrm{Aabcde}$ \\
Santo Inácio Vermelho & $3,46 \pm 1,7 \mathrm{Bb}$ & $16,7 \pm 4,5 \mathrm{Acde}$ \\
CNCX 251-76e & $22,5 \pm 1,8 \mathrm{Ba}$ & $26,3 \pm 5,2 \mathrm{Aa}$ \\
Roxinho 1 & $3,6 \pm 0,6 \mathrm{Bb}$ & $17,5 \pm 3,2 \mathrm{Aabcd}$ \\
BRS Punjante & $4,13 \pm 0,3 \mathrm{Bb}$ & $11,1 \pm 6,7 \mathrm{Ade}$ \\
Paraguaçu & $3,1 \pm 0,2 \mathrm{Bb}$ & $18,9 \pm 3,4 \mathrm{Aabcd}$ \\
BRS Tumucumaque & $2,86 \pm 0,2 \mathrm{Bb}$ & $13,6 \pm 2,3 \mathrm{Acde}$ \\
BRS Marataoã & $5,46 \pm 0,7 \mathrm{Bb}$ & $20,0 \pm 1,6 \mathrm{Aabcd}$ \\
\hline
\end{tabular}

* Médias com as mesmas letras minúsculas na coluna e mesmas letras maiúsculas na linha não diferem entre si pelo teste de Tukey a $5 \%$ de probabilidade com mais ou menos o desvio padrão.

Tabela 3. Taxa de crescimento $\left(\mathrm{cm} \mathrm{dia}^{-1}\right)$ das raízes aos cinco dias após a semeadura e submetidas ao tratamento com água e PEG6000. Table 3. Growth rate $\left(\mathrm{cm}\right.$ day $\left.{ }^{-1}\right)$ of the roots at five days after sowing and treated with water and PEG6000.

\begin{tabular}{lcc}
\hline Genótipos & Água & \multicolumn{1}{c}{ PEG6000 } \\
\hline Pitiuba & $4,53+0,7 \mathrm{Aab}$ & $1,23+0,3 \mathrm{Bb}$ \\
Patativa & $4,68 \pm 1,0 \mathrm{Aab}$ & $0,87 \pm 0,3 \mathrm{Bb}$ \\
Epace 10 & $3,80 \pm 0,4 \mathrm{Aabc}$ & $1,15 \pm 0,1 \mathrm{Bb}$ \\
Sempre verde & $3,95 \pm 1,4 \mathrm{Aab}$ & $0,87 \pm 0,3 \mathrm{Bb}$ \\
Setentão & $3,45 \pm 0,5 \mathrm{Abc}$ & $0,71 \pm 0,1 \mathrm{Bb}$ \\
Pingo de Ouro & $1,80 \pm 0,5 \mathrm{Ac}$ & $0,86 \pm 0,3 \mathrm{Bb}$ \\
Pingo de Ouro 1,2 & $5,59 \pm 0,9 \mathrm{Aa}$ & $1,13 \pm 0,2 \mathrm{Bb}$ \\
Pageú & $3,90 \pm 0,4 \mathrm{Aba}$ & $0,77 \pm 0,3 \mathrm{Bb}$ \\
Santo Inácio vermelho & $3,76 \pm 0,9 \mathrm{Aabc}$ & $0,57 \pm 0,05 \mathrm{Bb}$ \\
CNCX 251-76e & $5,58 \pm 1,0 \mathrm{Aa}$ & $4,72 \pm 0,4 \mathrm{Ba}$ \\
Roxinho 1 & $3,86 \pm 0,6 \mathrm{Aab}$ & $0,52 \pm 0,1 \mathrm{Bb}$ \\
BRS Punjante & $2,78 \pm 1,3 \mathrm{Abc}$ & $0,76 \pm 0,3 \mathrm{Bb}$ \\
Paraguaçu & $4,44 \pm 0,7 \mathrm{Aab}$ & $0,43 \pm 0,05 \mathrm{Bb}$ \\
BRS Tumucumaque & $3,10 \pm 0,5 \mathrm{Abc}$ & $0,35 \pm 0,05 \mathrm{Bb}$ \\
BRS Marataoã & $4,55 \pm 0,4 \mathrm{Aab}$ & $0,96 \pm 0,14 \mathrm{Bb}$ \\
\hline
\end{tabular}

*Médias com as mesmas letras minúsculas na coluna e mesmas letras maiúsculas na linha não diferem entre si pelo teste de Tukey a $5 \%$ de probabilidade, com mais ou menos o desvio padrão.

Para número de raízes laterais, números de verticilos e massa seca da raiz (Figura 1), não houve diferença entre genótipos, apenas entre tratamentos com e sem PEG6000. Comparando os tratamentos, os genótipos submetidos ao tratamento PEG6000 apresentaram menor quantidade de raízes laterais. $\mathrm{O}$ mesmo ocorreu para o número de verticilos e massa seca que foram menores no tratamento PEG6000.

Após as avaliações da raiz, o genótipo CNCX 251-76E destacou-se como tolerante, visto que o mesmo mostrou bom desenvolvimento do sistema radicular. Alguns genótipos foram considerados susceptíveis ao déficit hídrico, porém, destacaram-se os genótipos Pingo de Ouro, Santo Inácio Vermelho e BRS Tumucumaque por apresentarem raízes mais superficiais, bem como o menor comprimento e número médio de raízes.

\subsection{Estresse hídrico simulado com o método do Screening Box}

A germinação de sementes e o crescimento inicial das plantas de todos os genótipos foram normais. Cerca de seis dias após o término da irrigação, os efeitos do estresse começaram a aparecer. Alguns genótipos se mostraram suscetíveis, e as diferenças entre eles se tornaram visível e progressivamente mais pronunciada com o avanço dos dias do estresse hídrico. Os efeitos do estresse foram vistos pela primeira vez nas folhas unifoliadas, que se tornaram murchas, seguido pelos trifólios emergentes e, finalmente, a própria ponta de crescimento seca.

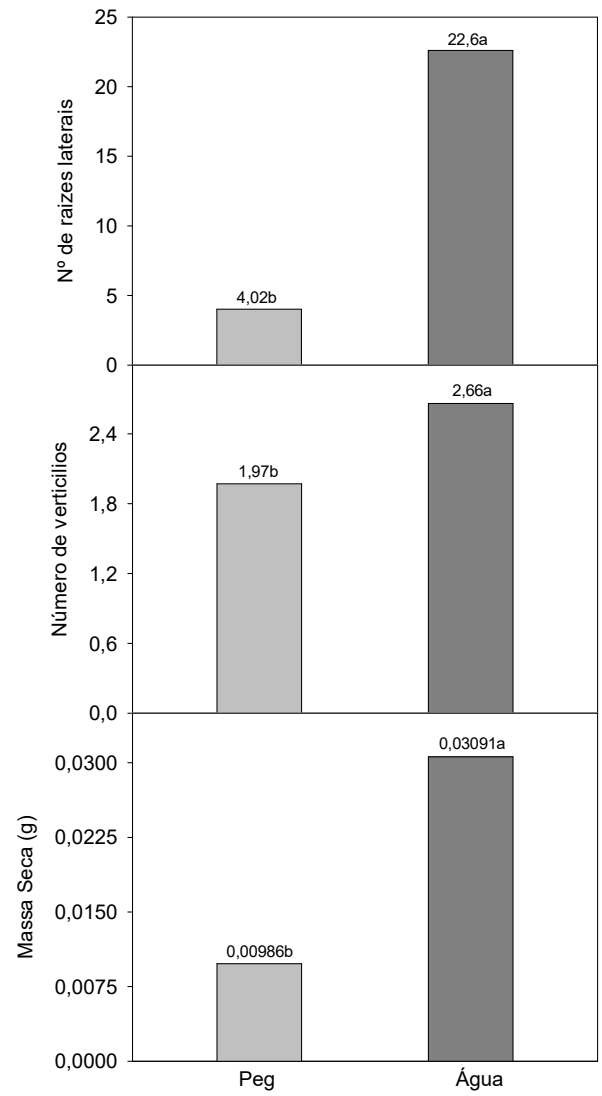

Figura 1. Número de raízes laterais, números de verticilos e massa seca da raiz dos tratamentos com e sem PEG6000.

Figure 1. Number of lateral roots, whorl numbers and root dry mass of treatments with and without PEG6000.

Em relação ao teste de média houve diferença estatística entre os genótipos de feijão-caupi, de acordo com as plântulas murchas por dia (Tabela 4). Os genótipos 9, 8, 10, $14,12,5,2,1$ e 13 não diferiram estatisticamente entre si. Esses genótipos apresentaram maior susceptibilidade ao déficit hídrico. Já os genótipos 15, 11, 3, 6, 7 e 4 foram selecionados como tolerantes, uma vez que mostraram um atraso no processo de murchamento.A metodologia utilizada possibilitou identificar os genótipos com melhores características de tolerância e suscetibilidade ao déficit hídrico em nível de plântulas, demostrado ser um método prático e eficiente, fornecendo uma abordagem simplificada para o estudo da tolerância ao déficit hídrico da cultura de feijão-caupi. 
Tabela 4. Plantas Murchas por dia.

Table 4. Wilt plants per day.

\begin{tabular}{ll}
\hline Genótipos & Médias \\
\hline 9 Santo Inácio vermelho & $0.000000 \mathrm{a}$ \\
8 Pageú & $0.000000 \mathrm{a}$ \\
10 CNCX 251-76e & $0.000000 \mathrm{a}$ \\
14 BRS Tumucumaque & $0.000000 \mathrm{a}$ \\
12 BRS Punjante & $0.000000 \mathrm{a}$ \\
5 Setentão & $0.000000 \mathrm{a}$ \\
2 Patativa & $0.000000 \mathrm{a}$ \\
1 Pitiuba & $0.000000 \mathrm{a}$ \\
13 Paraguaçu & $0.750000 \mathrm{a}$ \\
15 BRS Marataoã & $1.750000 \mathrm{~b}$ \\
11 Roxinho 1 & $1.750000 \mathrm{~b}$ \\
3 Epace 10 & $1.750000 \mathrm{~b}$ \\
6 Pingo de Ouro & $3.500000 \mathrm{~b}$ \\
7 Pingo de Ouro 1,2 & $3.500000 \mathrm{~b}$ \\
4 Sempre Verde & $3.500000 \mathrm{~b}$ \\
\hline
\end{tabular}

*Médias com as mesmas letras minúsculas, não diferem entre sì pelo Teste de Scott-Knott (1974) a 5\% de probabilidade.

A partir da curva de murchamento permanente foi possível selecionar os genótipos mais tolerantes e mais suscetíveis. Os dados sobre a percentagem de murcha em dias diferentes após o término da irrigação indicam estes genótipos como os mais susceptíveis à seca, Santo Inácio Vermelho e BRS Tumucumaqueque apresentaram maior rapidez no murchamento das plântulas (Figura 2) e, outros dois genótipos, Pingo de Ouro 1,2 e BRS Marataoã como tolerantes à seca, uma vez que os mesmos apresentaram menores números de plântulas murchas e também apresentaram um atraso no processo de desidratação. No $14^{\circ}$ dia após retenção de água, 32\% das plantas de Santo Inácio e $54 \%$ das plantas do BRS Tumucumaque tinham murchado, enquanto Pingo de Ouro 1,2 e BRS Marataoã tinham 10\% e zero murchamento, respectivamente.

Os outros genótipos apresentaram variações de 21 a 43\% quanto à percentagem de murchamento. No $24^{\circ}$ dia os genótipos susceptíveis já estavam $100 \%$ murchos enquanto os tolerantes ainda tinham plantas vigorosas.

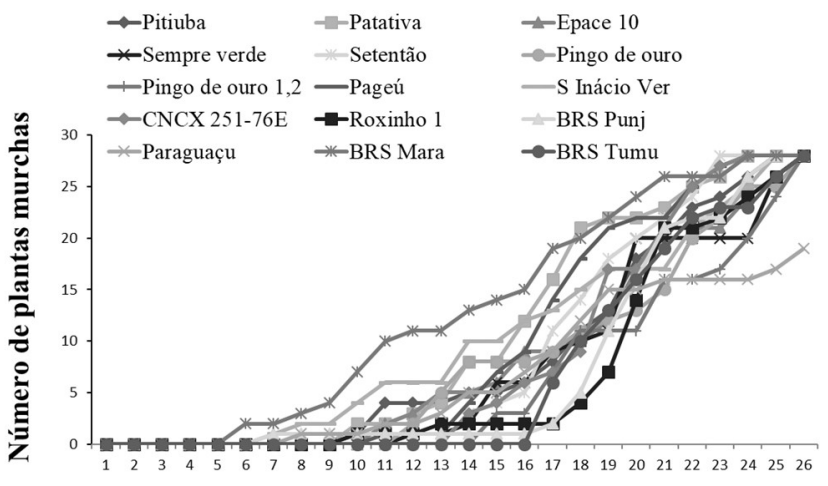

Dias após a suspensão

Figura 2. Curva de murcha ao longo dos dias após a suspensão da irrigação do experimento de Screening Box de 15 genótipos para tolerância à seca.

Figure 2. Wilt curve along the days after irrigation suspension of the Screening Box experiment of 15 genotypes for drought tolerance.

\section{DISCUSSÃO}

De acordo com Price et al. (2002) há o aumento do comprimento das raízes como resposta ao déficit hídrico. Taiz; Zeiger (2017), dizem que esse mecanismo pode ser considerado uma defesa contra a seca. Assim, o aumento do comprimento do sistema radicular dos genótipos submetidas ao déficit hídrico simulado indica ser uma alternativa da planta de ir à busca de água que poderia estar em maior profundidade.

Alguns genótipos, como CNCX 251-76E e Pingo de ouro 1,2 também diferiram dos demais quando submetido ao tratamento com água. Para este genótipo não se tem relatos quanto a sua tolerância a seca, já para o genótipo Pingo de Ouro 1,2, Nascimento et al. (2011) verificaram que este genótipo apresentou tolerância ao déficit hídrico.

A tolerância ao déficit hídrico varia com o genótipo, sendo que algumas plantas desenvolvem mecanismos de adaptação, tornando-se mais eficientes na absorção de água do solo, especialmente através do desenvolvimento de um extenso e profundo sistema radicular e de características da parte aérea, como adequação da área foliar, rápido fechamento dos estômatos e manutenção de uma reduzida temperatura foliar, dentre outros (REIS et al., 2006).

Em relação ao número de raízes laterais, número de verticilos e massa seca, foram observados menores valores para o tratamento PEG6000, isso, pode ter sido devido o déficit hídrico afeta praticamente todos os aspectos do crescimento da planta, causando redução na expansão celular (HSIAO, 1990) e menor desenvolvimento de raízes nestas condições (POLANÍA et al., 2009).

Nascimento et al. (2011) ao estudarem a tolerância ao déficit hídrico em 20 genótipos de feijão-caupi no período reprodutivo, selecionaram entre os genótipos tolerante o Pingo de Ouro 1,2 com características tolerante a seca e os genótipos Pingo de Ouro e Santo Inácio Vermelho como intolerantes ao déficit hídrico moderado.

Os resultados do método do Screening Box corroboram com os resultados de Nascimento et al. (2011) e Oliveira et al. (2004) que demonstraram que os genótipos Pingo de Ouro 1,2 e BRS Marataoã apresentam características adequadas a tolerância ao déficit hídrico.

Estudo constata que o genótipo Pingo de Ouro 1,2 apresentam ampla adaptabilidade e alta estabilidade aos ambientes do Nordeste do Brasil (Barros et al. (2013), assim como a cultivar BRS-Marataoã é moderadamente tolerante ao déficit hídrico (EMBRAPA, 2004). Quanto aos genótipos identificados com maior sensibilidade ao déficit hídrico (Figura 2), o genótipo Santo Inácio Vermelho apresenta características de sensibilidade ao déficit hídrico, porém a cultivar BRS Tumucumaque possui características de tolerância (EMBRAPA, 2009), o que não foi verificado neste estudo.

A metodologia de Screening Box foi utilizada com sucesso por Singh; Matsui (2002), que validaram esse método para rápida identificação de genótipos promissores para tolerância a seca e confirmaram o mesmo resultado utilizando outras metodologias com plantas em estádios mais avançados de desenvolvimento, fato também observado no presente estudo.

As duas metodologias demostraram resultados semelhantes, como por exemplo, em ambas metodologias os genótipos Santo Inácio Vermelho e BRS Tumucumaque, foram susceptíveis ao déficit hídrico. Uma vez que os resultados de estresse simulado com PEG6000 e o método do Screening Box mostraram algumas semelhanças, o método do Screening Box é mais prático e a capacidade de possibilitar 
grande número de plantas/ linhas, faz deste método útil para a identificação de germoplasma de feijão-caupi a esse tipo de estresse (SINGH et al., 1999a), além disso, os resultados são mais concretos quando comparados com resultados obtidos na literatura. O método com PEG6000, mesmo levando menos tempo para o desenvolvimento do experimento é mais trabalhoso, é um método destrutivo das plântulas, diferente do método de caixas que é simples e não destrutivo, as plantas tolerantes à seca podem ser salvas e transplantadas para outros testes como teste de progênies e seleção.

\section{CONCLUSÕES}

As duas metodologias mostraram-se eficiente na seleção de genótipos de feijão-caupi, porém, os resultados do método de Screening Box corroboram com resultados apresentados na literatura. Entre os genótipos estudados o Santo Inácio Vermelho e BRS Tumucumaque foram os mais sensíveis à seca, em ambas as metodologias.

\section{REFERÊNCIAS}

ASSIS JÚNIOR, J. O.; LACERDA, C. F. de; SILVA, F. B.; SILVA, F. L.B.; BEZERRA, M. A; GHEYI, H. R. Produtividade do feijão de corda e acúmulo de sais no solo em função da fração de lixiviação e da salinidade da água de irrigação. Engenharia Agrícola, Jaboticabal, v. 27, n. 3, p. 702-713, 2007. DOI: https://doi.org/10.1590/S0100-69162007000400013

BARROS, M. A.; DE MOURA ROCHA, M.; GOMES, R. L. F.; DAMASCENO, K. J.; DAS NEVES, A. C. Adaptabilidade e estabilidade produtiva de feijão caupi de porte semiprostrado. Pesquisa Agropecuária Brasileira, Brasília, v. 48, n. 4, p. 403-410, 2013.

COELHO, J. B. M.; BARROS, M. F. C.; BEZERRA NETO, E.; CORREA, M. M. Comportamento hídrico e crescimento do feijão Vigna cultivado em solos salinizados. Revista Brasileira de Engenharia Agrícola e Ambiental, v. 17, n. 4, p. 379-385, 2013. DOI: http://dx.doi.org/10.1590/S1415-43662013000400004

EMBRAPA_Empresa Brasileira de Pesquisa Agropecuária. BRS TUMUCUMAQUE: cultivar de feijão-caupi para o Estado do Amapá. Macapá: Embrapa Amapá, 2009. Não paginado. Disponível em $<$ https://www.embrapa.br/busca-de-publicacoes//publicacao/346883/brs-tumucumaque-cultivar-de-feijaocaupi-para-o-estado-do-amapa $>$. (Folder).

EMBRAPA_Empresa Brasileira de Pesquisa AgropecuáriaBRS-Marataõa: cultivar de feijão-caupi com grão sempre verde. Teresina: Embrapa Meio Norte. 2004, 8p. Disponível

$<$ https:/www.infoteca.cnptia.embrapa.br/infoteca/handle/ doc/64335>. (Folder)

FERREIRA, D. F. Sisvar: a computer statistical analysis system. Ciência e Agrotecnologia, Lavras, v. 35, n. 6, p 1039-1042, 2011. DOI: http://dx.doi.org/10.1590/S141370542011000600001

FERREIRA, A.C.T.; FELITO, R.A.; ROCHA, A.M.; CARVALHO, M.A.C.; YAMASHITA, O.M. Water and salt stresses on germination of cowpea (Vignaungui culata cv. BRS Tumucumaque) seeds. Revista Caatinga, Mossoró, v. 30, n. 4, p. 1009-1016, 2017. DOI: http://dx.doi.org/10.1590/1983-21252017v30n422rc.

FREITAS, R. M. O. de; DOMBROSKI, J. L. D.; FREITAS, F. C. L. de; NOGUEIRA, N. W.; PINTO, J. R. de S.
Respostas fisiológicas de feijão-caupi sob estresse hídrico e reidratação em plantio direto e convencional. Revista Caatinga, Mossoró, v. 30, n. 3, p. 559-567, 2017.

GWATHMEY, C. O.; HALL, A. E. Adaptation to midseason drought of cowpea genotypes with contrasting senescence traits. Crop Sciense, v. 32, n. 3, p. 773-778, 1992. DOI: https://dx.doi.org/10.2135/cropsci1992.0011183X003200 030039x

HSIAO, T. C. Measurements of plant water status. American Society of Agronomy, New York, p. 244-280, 1990.

MENDES, R. M. S.; TÁVORA, F. J. A. F.; PINHO, J. L. N.; PITOMBEIRA, J. B. Relações fonte-dreno em feijão-decorda submetido à deficiência hídrica. Ciência Agronômica, Fortaleza, v. 38, n. 1, p. 95-103, 2007.

NASCIMENTO, S. P. D.; BASTOS, E. A.; ARAÚJO, E. C.; FREIRE FILHO, F. R.; SILVA, E. M. D. Tolerance to water déficit of cowpea genotypes. Revista Brasileira de Engenharia Agrícola e Ambiental, Campina Grande, v. 15 , n. $8, \quad$ p. $853-860$, 2011. DOI: http://dx.doi.org/10.1590/S1415-43662011000800013

OLIVEIRA, I. J. de; FONTES, J. R. A.; DAMASCENO, K. J. E. S.; ROCHA, M. M. BRS Marataoã - Cultivar de Feijão-Caupi com Grão Sempre Verde para o Amazonas. Manaus: Embrapa Amazônia Ocidental, 2004. 4 p. (Comunicado Técnico 107).

POLANÍA, J. A.; RAO, I. M.; BEEBE, S.; GARCÍA, R. Desarrollo y distribucíon de raíces bajo estrés por sequia enfrígolcomún (Phaseolusvulgaris L.) enun sistema de tubos consuelo. Agronomia Colombiana, Bogota, v. 27, n. 1, p. 25-32, 2009.

PRICE, A. H.; STEELE, K. A.; GORHAM, J.; BRIDGES, J. M.; MOORE, B. J.; EVANS, J. L.; RICHARDSON, P.; JONES, R. G. W. Upland rice grown in soil-filled chambers and exposed to contrasting water-deficit regimes. I. Root distribution, water use and plant water status. Field Crops Research, v. 76, n. 1, p. 11-24, 2002. DOI: https://doi.org/10.1016/S0378-4290(02)00012-6

REIS, G. G.; REIS, M. G. F.; FONTAN, I. C. I.; MONTE, M. A.; GOMES, A. M.; OLIVEIRA, C. H. R. Performance of Eucalyptus spp. clones under different levels of soil water availability in the field-root and aboveground growth. Revista Arvore, Viçosa, v. 30, n. 6, p. 921-931, 2006. DOI: http://dx.doi.org/10.1590/S0100-67622006000600007

SCOTT, A. J.; KNOTT, M. A cluster analysis method for grouping means in the analysis of variance. Biometrics, Washington, v. 30, n. 3, p. 507-512, 1974. DOI: https://dx.doi.org/10.2307/2529204

SINGH, B. B.; MATSUI, T. Cowpea varieties for drought tolerance. In: FATOKU, C. A.; TARAWALI, S.A.; SINGH, B. B.; KORMAWA, P.M.; TAMÒ, M. Challenges and opportunities for enhancing sustainable cowpea production. Ibadan: International Institute of Tropical Agriculture, 2002. p. 287-300.

SINGH. B. B.; MAI-KODOMI, Y.; TERAO T. A simple screening method for drought tolerance in cowpea. The Indian Journal of Genetics and Plant Breeding, New Delhi, v. 59, n. 2, p. 211-220, 1999a. DOI:

SOUZA, G. M.; CARDOSO, V. J. M. Effects of different environmental stress on seed germination. Seed Science Technology, v. 28, n. 3, p. 621-630, 2000.

TAIZ, L.; ZEIGER, E. Fisiologia vegetal. 6. ed. Porto Alegre: Artmed, 2017. 888p 